\title{
PROTEÇÃO DA PRIVACIDADE ONLINE NA PORNOGRAFIA DE VINGANÇA
}

\author{
Ana Cláudia Farranha Santana ${ }^{1}$ \\ Amanda Nunes Lopes Espiñeira Lemos ${ }^{2}$ \\ Juliana Thomazini Nader Simões ${ }^{3}$
}

\begin{abstract}
Resumo: Este trabalho apresenta um estudo comparado entre o Brasil e os Estados Unidos sobre a pornografia de vingança, avaliando a efetividade dos instrumentos existentes para a proteção das vítimas e a reparação dos danos dessa prática, a partir de uma análise qualitativa. Parte-se das seguintes perguntas de pesquisa: De que forma o conceito de privacidade se aplica ao ambiente virtual? Como as tecnologias possibilitaram o desenvolvimento de novas formas de intimidade, bem como de práticas como a pornografia de vingança? Analisa-se o direito à privacidade dentro da concepção de esfera pública e privada no ambiente virtual e as novas formas de intimidade nesse contexto, apontando possíveis caminhos para melhorias na legislação vigente sobre a temática.
\end{abstract}

Palavras-chave: pornografia de vingança; direito à privacidade; Marco Civil da Internet; Brasil; Estados Unidos.

\section{INTRODUÇÃO}

Este trabalho objetiva compreender a prática conhecida como pornografia de vingança e sua inserção dentro do contexto de formas de privacidade e intimidade no ambiente virtual, diante das novas tecnologias. Para tanto, busca-se entender o direito à privacidade, situando-o dentro da concepção de esferas pública e privada e das novas práticas de compartilhamento de mídia digital. A pertinência desta pesquisa decorre da atualidade do tema e a recorrência de casos de pornografia de vingança, ante o desenvolvimento tecnológico que trouxe diversos benefícios para os relacionamentos humanos. Os instrumentos de comunicação fazem com que as distâncias se tornem pouco relevantes, tendo em vista que mensagens, ligações e videoconferências possibilitam

\footnotetext{
${ }^{1}$ Mestre em Ciência Política pela Universidade Estadual de Campinas e doutora em Ciências Sociais pela Universidade Estadual de Campinas. É professora adjunta da Faculdade de Direito - Universidade de Brasilia FD/UnB, desenvolvendo atividades na área de Direito e Gestão Pública. Universidade de Brasília - UnB, Distrito Federal - Brasil. E-mail: anclaud@uol.com.br

2 Doutoranda em Direito na Universidade de Brasília (UnB)-2019-2022. Mestre em Direito pela UnB, bolsista CAPES. Advogada. Bacharel em Direito pela Universidade Federal da Bahia (UFBA). Membro dos grupos de pesquisa Observatório de Políticas Públicas (GEOPP), Grupo de Estudos em Direito das Telecomunicações (GETEL). Revisora das Revistas de Direito Setorial e Regulatório (Journal of Law and Regulation) e da Revista de Direito, Estado e Telecomunicações (RDET). Universidade de Brasília - UnB, Distrito Federal - Brasil. E-mail: amandaespineira@gmail.com

${ }^{3}$ Graduanda em Direito na Universidade de Brasília - UnB; Universidade de Brasília - UnB, Distrito Federal Brasol. E-mail: juliana.thomazinins@gmail.com
} 
conversas em tempo real. Essas facilidades vêm sendo exploradas também no campo das relações íntimas. O compartilhamento de mídia íntima é atitude que vem se disseminando, abrangendo todos os grupos sociais e etários. O envio de fotos e vídeos entre casais ajuda a manter relacionamentos, criando laços de intimidade e cumplicidade. Os problemas surgem quando esses laços são quebrados, e uma das partes busca atingir a outra, divulgando conteúdos trocados dentro de uma relação de confiança.

A pornografia de vingança é a prática de distribuir mídia íntima, em especial por meio da internet, sem que a pessoa retratada tenha consentido com a publicação do material. Por ser uma conduta com surgimento relativamente recente nos moldes em que vem ocorrendo, tendo se consolidado no meio virtual, ainda existem dificuldades sobre como abordar o problema. Este trabalho buscar apontar alguns caminhos que podem ser seguidos, tanto utilizando os instrumentos já disponíveis no ordenamento jurídico, quanto almejando novas soluções. Ele também busca refletir sobre a efetividade dos instrumentos existentes atualmente no ordenamento jurídico brasileiro e americano para a proteção das vítimas e a reparação dos danos causados pela pornografia de vingança, apontando possíveis caminhos para melhorias na legislação vigente.

Parte-se dos seguintes problemas de pesquisa: De que forma o conceito de privacidade se aplica ao ambiente virtual? Como as tecnologias possibilitaram o desenvolvimento de novas formas de intimidade, bem como de práticas como a pornografia de vingança? Metodologicamente tratase de um estudo qualitativo comparado entre o Brasil e os Estados Unidos sobre a pornografia de vingança. Analisa-se a prática nos dois países, a partir da legislação que disciplina o tema, bem como de casos decididos nas Cortes americana, avaliando, assim, a efetividade dos instrumentos existentes para a proteção das vítimas e a reparação dos danos dessa prática. Trata-se, portanto, de uma pesquisa documental com análise de legislação comparada e estudo de caso.

Como hipóteses da investigação tem-se que o Brasil ainda não possui uma regulamentação adequada para tratar do tema, mesmo com a recente aprovação da Lei Geral de Proteção de Dados, Lei n. 13.709/2018. Dessa forma, o Judiciário vem dando a tônica das decisões no assunto, a partir da interpretação de diversos casos, dentre os emblemáticos aqui trabalhados. Enquanto os Estados Unidos, diante da jurisprudência robusta construída e do modelo juridico permitir essa interferência mais direta do Judiciário para regular, possui maior efetividade em punir casos de pornografia de vingança. O que se soma ao fato de os temas de assédio e esturpro naquele país serem tratados com bastante austeridade e punitivismo, o que se extende para os casos virtuais.

Assim, divide-se o trabalho em quatro partes. Inicialmente trata-se da noção de privacidade dentro do redimensionamento da noção de público e privado no ambiente virtual. Nesse contexto, introduz-se a privacidade online e as novas práticas de compartilhamento de mídia digital. Estuda- 
se, então, a proteção garantida às vítimas, além das formas de reparação dos danos, nos ordenamentos jurídicos dos Estados Unidos e do Brasil respectivamente.

\section{REDIMENSIONAMENTO DA NOÇÃO DE PÚBLICO E PRIVADO: PRIVACIDADE ONLINE E AS NOVAS PRÁTICAS DE COMPARTILHAMENTO DE MÍDIA DIGITAL}

Importante compreender a ressignificação do conceito de privacidade no meio virtual, onde os indivíduos, muitas vezes, se expõem voluntariamente e também é um ambiente no qual o potencial de coleta, processamento e utilização dos dados pessoais é aumentado consideravelmente diante do avanço da tecnologia da informação. Diante desses novos fenômenos, sobre os interesses múltiplos na coleta começam a ser desenhadas regulações de comportamentos e direitos de proteção dos dados pessoais, que afetam diretamente no processo econômico e nas relações comerciais contemporâneas. A construção do indivíduo como sujeito de direitos e obrigações determinadas por lei acentua a necessidade de proteção ao seu espaço de privacidade. Apesar de consagrado em diversos instrumentos normativos, o direito à privacidade é de difícil definição, podendo adquirir diversas interpretações, conforme o contexto, tornando a tarefa de precisar uma única definição para o termo uma empreitada árdua. Contudo, alguns traços básicos podem ser estabelecidos para caracterizar o que se considera privacidade e, consequentemente, definir uma esfera essencial que deve ser abrangida pela proteção do direito fundamental à vida privada.

Para Nissembaum (2004) é justamente essa característica contextual que detém proeminência ao se determinar se um evento é ou não protegido pelo direito à privacidade. Em sua Teoria da Integridade Contextual, a autora defende que as normas sociais governando o fluxo de informações varia conforme o contexto. De forma que a expectativa de privacidade que se pode ter em determinado evento será condicionada a convenções sociais vigentes, cultura, aspectos políticos, personagens envolvidas e ao tipo de informação em questão. Abandona-se a dicotomia entre público e privado para inserir na equação as nuances sociais incidindo sobre o fato - ensejando, ou não, a proteção da privacidade.

É importante entender que o direito de privacidade deve ser compreendido como uma forma de controle dos usuários sobre suas próprias informações, o que envolve o elemento consentimento como principal motor dessa cessão de privacidade (DONEDA, 2006).

Isso quer dizer que a informação compartilhada com amigos ou familiares pode ser ainda considerada privada, a depender das circunstâncias em que foi partilhada, diferentemente daquilo que foi apresentado a estranhos. A natureza da relação entre o indivíduo que compartilha a informação e aquele que a recebe pode alterar o nível de privacidade que se pode razoavelmente esperar em relação à informação. A cada etapa de sua evolução, os meios de comunicação apresentaram um novo desafio, tencionando os limites estabelecidos para a proteção da privacidade. 
Com a Internet essa noção de proteção à privacidade se ressignifica. Por vezes, a falta de clareza de dispositivos legais visando proteger a privacidade leva a uma visão binária entre os espaços público e privado. Essa nova conjuntura traz muitas oportunidades, e ainda mais incertezas.

Surgem mais possibilidades para que a privacidade seja violada, pois cada usuário com acesso à internet pode inserir na rede conteúdo que detenha, sobre quem desejar, sem qualquer limitação. Após publicado online, todo esse material permanece disponível, sendo extremamente difícil a retirada total dessa informação da rede. Paralela aos novos desafios para a proteção da privacidade começa a se desenvolver uma perspectiva diferente sobre a própria privacidade. A construção da identidade individual passa também pelo mundo virtual, com o compartilhamento de dados e informações sobre si. O meio eletrônico constitui um novo ambiente para a formação de laços sociais, onde a moeda de troca é o intercâmbio consensual de informações pessoais. Conforma-se um novo paradoxo no qual os indivíduos não só aceitam, como desejam expor suas vidas no ambiente público online, desde que possam ter controle sobre essas informações e quem terá acesso a elas, de forma a resguardar o nível de privacidade que desejam manter. Gagnier (2011) destaca a complexidade da questão, apontando como existe o desejo de manter privadas as mesmas informações pessoais tornadas públicas, de acordo com a audiência a que tais dados poderão estar disponíveis.

Solove (2007) apresenta como cada meio de comunicação afetou a privacidade. As invasões da privacidade perpetradas pela imprensa marrom ganharam novas dimensões com a internet. As facilidades proporcionadas pela rede alteraram vários aspectos de como se dá a comunicação, tanto entre as pessoas quanto na divulgação de informações. A demarcação entre o espaço público e o privado se torna mais nebulosa, ante a ausência de barreiras físicas para a delimitação dos espaços. A privacidade a ser protegida inclui agora, também, o campo digital. A divulgação de informações em larga escala não mais está restrita a veículos da imprensa tradicional. Cada indivíduo pode expor suas ideias, opiniões, e relatar acontecimentos (que tenha ou não presenciado) livremente, inclusive a respeito de outras pessoas. Evidente que o conceito de privacidade, e o escopo de proteção garantido por tal direito, não pode permanecer o mesmo num contexto de superexposição voluntária, como é o das redes sociais.

Para Holland (2010, p.894) "o processo de sociabilidade que ocorre dentro dessas redes é impulsionado por nossa necessidade de preservar os benefícios da comunidade em um mundo mais estilhaçado"”. A organização social que se desenvolve a partir dessa nova modalidade de comunicação acaba levando os indivíduos a aderirem às redes sociais, para que não se tornem excluídos de seu próprio grupo de convívio social, ou não tomem conhecimento dos mais recentes

\footnotetext{
4 "the process of sociality that occurs within these networks is driven by our need to preserve the benefits of community in a more splintered world”. (Tradução nossa)
} 
acontecimentos (seja sobre futilidades ou sobre assuntos mais complexos). E o sentimento de comunidade, consolidado nessas redes, encoraja todos a compartilharem cada vez mais suas informações pessoais. Contudo, concomitantemente, existe o desejo de controlar quem tem acesso às informações compartilhadas. Resta caracterizada uma situação na qual, apesar de voluntariamente disponibilizada online, a informação pessoal deve continuar a ser protegida daqueles que o usuário não pretendia que tivessem acesso a ela.

Destaca-se ainda outro fenômeno nesse contexto qual seja as constantes mudanças nas políticas de privacidade e termos de uso, e a falta de clareza quanto ao escopo de privacidade protegido em determinado contexto que ajudam a criar uma ilusão de privacidade. As redes sociais mais populares apresentam uma característica em comum, que favorece essa falsa percepção de privacidade. Em todas elas o destaque está, quase exclusivamente, nas informações compartilhadas pelos usuários. O papel desempenhado pelos sites, posicionados, como descrito por Holand (2010, p.925), "como um terceiro beneficiário velado de trocas discretas entre contatos e o fluxo de

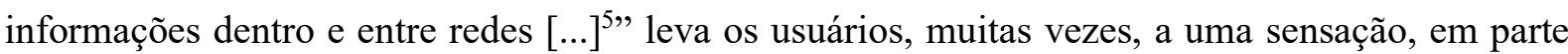
equivocada, de que sua privacidade está sendo protegida. Stepanovic $(2014$, p.174) defende que “[...] violação da privacidade ocorre quando não damos o nosso consentimento para divulgar certas informações. Enquanto estivermos cientes das regras e as aceitarmos, a privacidade não é um problema." "Esse quadro acaba por incentivar os indivíduos a compartilharem informações pessoais sensíveis, de forma que talvez não o fariam se concebessem a real dimensão da privacidade que lhes é assegurada.

Novas práticas surgem com a multiplicação de redes sociais e aplicativos usados para comunicação. A funcionalidade dos smartphones com multiplicidade de funções passou a ser explorada também no campo das relações íntimas. A gravação de vídeos em momentos de intimidade do casal, o envio de mensagens de teor sexual (prática conhecida como sexting) e o compartilhamento com o parceiro ou parceira de fotos sensuais - popularmente conhecidas como "nudes" - tem se tornado cada vez mais comum.

O compartilhamento de mídia íntima entre casais tem sido relatado como uma prática positiva não só para os relacionamentos, como também algo socialmente benéfico. Além de consistir em uma atividade sexual prazerosa, o uso da tecnologia permite a manutenção de uma vida sexual ativa entre os parceiros, criando uma nova forma de interação que independente da distância física a que possam estar sujeitos. Contudo, a utilização da tecnologia no contexto de intimidade dos casais tem-se mostrado uma prática problemática, especialmente com o fim de relacionamentos.

\footnotetext{
5 “[...] as a veiled third-party beneficiary of discrete exchanges between contacts and the flow of information within and across networks" (Tradução nossa)

6 "[...] violation of privacy occurs when we do not give our consent to disclose certain information. As long as we are aware of the rules and accept them, privacy is not a problem". (Tradução nossa)
} 
O envio de uma foto implica a existência de laços de confiança entre o casal. O rompimento desses laços, com o fim da relação ou até mesmo ainda dentro dela, torna o indivíduo retratado na foto suscetível ao arbítrio do ex-companheiro. Ainda, o maior anonimato e distanciamento possibilitado pelo envio de fotos ou vídeos por intermédio da internet, principalmente por celulares, permite que as pessoas se expressem mais livremente, de forma que habitualmente não o fariam. Assim os indivíduos constroem e mantém relacionamentos, aprendem a expressar sua sexualidade com maior confiança, superam inibições, e se sentem mais confortáveis para experimentar novos comportamentos sexuais, muitas vezes quebrando com os padrões socialmente estabelecidos de conduta sexual.

Pesquisas indicam que o compartilhamento de mídia íntima não está restrito a comunidades específicas, podendo ser observado em todos as faixas etárias sexualmente ativas e grupos sociais. Bambauer (2014, p. 2034) aponta dados de pesquisa realizada nos Estados Unidos, em 2012, segundo a qual $57 \%$ dos homens e $47 \%$ das mulheres questionados já haviam recebido uma imagem íntima por mensagem em seus celulares. O mesmo estudo apontou que 35\% das mulheres e 38\% dos homens já haviam enviado alguma imagem íntima para o parceiro ou parceira. Entretanto, essa prática não é isenta de perigos. O risco de vazamento do conteúdo de teor sexual - intencionalmente, por aqueles que tiveram acesso, ou mesmo involuntariamente. Dados relatados por Bambauer (2014, p. 2034) descrevem que 72\% dos entrevistados admitem existirem riscos para suas carreiras, e $75 \%$ reconhecem a possibilidade de a prática trazer riscos para suas reputações.

Nesse contexto surgem condutas como a pornografia de vingança, que vem se tornando cada vez mais comum, produzindo consequências devastadoras para o alvo da exposição involuntária. Longe de ser apenas a divulgação de uma imagem pessoal, sem o consentimento da pessoa nela retratada, a pornografia de vingança é uma atitude perniciosa, pela qual o indivíduo busca humilhar, envergonhar e amedrontar sua vítima, com quem teve algum tipo de relacionamento afetivo. A existência de diversos sites com a única finalidade de publicar imagens e mensagens, expondo a vítima, demonstra o potencial de lesividade da pornografia de vingança e de outras práticas de exposição involuntária correlatas.

A divulgação online de uma informação pessoal, retirada de seu contexto original e sem qualquer preocupação em demonstrar a realidade, cria um registro permanente na vida da pessoa retratada, que pode afetar gravemente sua reputação (NUSSBAUM, 2012). Além disso, a pessoa pode sofrer com problemas psicológicos, que vão desde a incapacidade de voltar a confiar novamente em parceiros amorosos, até os casos de indivíduos que cometem suicídio. Também no campo profissional a vítima de pornografia de vingança pode ser amplamente prejudicada, tendo em vista que, cada vez mais, se torna comum a análise do conteúdo disponível online sobre o candidato antes de sua contratação. 
A divulgação de mídia sem o consentimento da pessoa retratada atinge de forma majoritária mulheres, possivelmente mais uma consequência do machismo que ainda permeia nossas relações sociais. A objetificação da mulher, fenômeno que ocorre habitualmente, se torna mais premente na internet, com a exposição involuntária de mulheres em casos de pornografia de vingança. A distribuição na internet de imagens, vídeos e mensagens, com o claro intuito de humilhar mulheres, tem efeitos que não se limitam à esfera digital, atingindo a vida das vítimas em suas perspectivas de futuro, na forma como se apresentam socialmente e na sua autoestima. Há clara violação da autonomia individual com a exposição não autorizada de conteúdo íntimo da pessoa na rede, tornando-o disponível para qualquer um com acesso à internet. Entretanto, a solução notoriamente indicada para evitar os possíveis transtornos decorrentes do compartilhamento de mídia íntima é se abster de tal prática. A solução da abstenção prejudica o debate quanto a possíveis remédios para enfrentar o problema real que acomete a vida daqueles que são involuntariamente expostos. Fortemente atrelada com a culpabilização das vítimas, a solução da abstenção apenas se furta a colocar em pauta o que vem acontecendo com frequência no espaço virtual.

Devem ser desenvolvidos mecanismos de proteção, a fim de que as pessoas que desejem trocar imagens e vídeos pessoais não estejam tão vulneráveis ao arbítrio do destinatário da mídia, ante os danos reais que podem ser causados na vida social e profissional da pessoa com a disponibilização involuntária desses conteúdos. Pode-se citar como exemplo o projeto "safernudes " " da ONG "coding rights" que tem exatamente a finalidade de compartilhar estratégias e ferramentas que podem ajudar as pessoas a espalharem seus nudes de uma forma um pouco mais segura, possibilitando, também a ampliação do debate sobre privacidade no mundo digital. Alguns países adotaram como caminho para a repressão da pornografia de vingança a criminalização da prática. Nos Estados Unidos, onde o debate jurídico sobre as formas de coibir esta prática violadora será melhor abordado no próximo tópico, existe ainda resistência em atuar contra a pornografia de vingança, mesmo nos Estados em que existem leis criminalizando-a. Já no Brasil, a exposição involuntária é matéria a ser debatida na esfera cível, a partir de disposições legais e constitucionais, como analisaremos a seguir.

\section{PROTEÇÃO DA PRIVACIDADE ONLINE NOS ESTADOS UNIDOS}

O debate sobre pornografia de vingança nos Estados Unidos está centrado, primordialmente, em um conflito de valores. Por um lado, não se pode limitar injustificadamente a liberdade de expressão dos indivíduos. Por outro, a proteção da privacidade deve ser garantida, bem como os

\footnotetext{
${ }^{7} \mathrm{http}$ ://www.codingrights.org/pt/manda-nudes/.
} 
danos causados à vítima devem ser reparados. Alguns estados da federação têm legislação própria sobre o tema, apesar de serem iniciativas limitadas. Outros estudam como legislar sobre a matéria, sem criar empecilhos ao exercício de direitos como liberdade de expressão e copyright. Conquanto seja importante o debate no nível estadual sobre o tema, com o fito de criar mecanismos legais de punição dos ofensores e proteção das vítimas, diversos autores defendem a necessidade de legislação federal específica acerca da pornografia de vingança. No âmbito federal, o Communications Decency Act - CDA - ganha destaque pelas implicações práticas decorrentes de seu texto. Em especial, o disposto na Seção 230, que garante imunidade aos intermediários pelas informações disponibilizadas por terceiros na rede. Com essa garantia, provedores de aplicações, como sites e aplicativos, não podem ser responsabilizados por dados divulgados por usuários por meio de suas plataformas.

Segundo Choi (2013) a opção legislativa de garantir imunidade aos intermediários teve como motivação incentivar o potencial gerativo da internet. Cabe recordar que a aprovação do CDA ocorreu em 1996, período em que crescia o número de usuários, e a internet ainda não havia se consolidado enquanto instrumento de criação e disseminação de conteúdo. Quanto à imunidade conferida pela Seção 230 do Communications Decency Act aos intermediários, Bambauer (2014, p.2090) considera ser esse o primeiro obstáculo, em casos de pornografia de vingança, do ponto de vista da efetividade da proteção da privacidade garantida por dispositivos legais, pois "enquanto a revelação inicial de mídias íntimas provavelmente causa algum dano, o maior dano vem da disponibilidade pública e do compartilhamento contínuo desses meios $[\ldots]^{8, "}$.

Com a proteção conferida pela Seção 230 do CDA aos provedores de aplicações na internet, não existem incentivos para que os intermediários auxiliem as vítimas de pornografia de vingança, retirando a mídia da rede ou fornecendo informações visando identificar quem disponibilizou o conteúdo online. Dessa forma, o dano inicial causado pela divulgação do material online é potencializado pela permanência do conteúdo acessível na rede e pelos compartilhamentos da mídia por usuários. Existe, ainda, uma grande discrepância entre o tratamento conferido a comunicações online e offline, devido à previsão da Seção 230 do CDA, quanto à possibilidade de responsabilização pelo conteúdo divulgado.

Com a popularização do acesso à internet, torna-se cada vez mais fácil para as pessoas em geral divulgarem conteúdos que poderão atingir um grande público, sem maiores preocupações quanto ao material que é publicado ou quanto às implicações que podem vir a decorrer do que está sendo distribuído. Outrossim, os provedores de aplicações, resguardados pela imunidade conferida pelo CDA, não precisam questionar a natureza dos conteúdos inseridos por usuários em suas

8 "while the initial revelation of intimate media likely causes some harm, the greater harm comes from the public availability and ongoing sharing of these media". (Tradução nossa) 
plataformas, já que não poderão ser responsabilizados pelo que foi exposto. Nesse contexto, vítimas de pornografia de vingança encontram grandes dificuldades para retirar a mídia íntima da rede e/ou para identificar o ofensor, de forma a possibilitar a busca por reparação pelo prejuízo causado e evitar a perpetuação do dano com a contínua disponibilidade do material na internet. O primeiro desafio para a criação de mecanismos que protejam as vítimas de pornografia de vingança, e permitam a retirada dos conteúdos violadores da internet é a proteção à liberdade de expressão. A Primeira Emenda à Constituição dos Estados Unidos ${ }^{9}$ assegura que nenhuma lei limitando a liberdade de expressão será aprovada pelo Congresso. Sendo esse um dos princípios de maior destaque no ordenamento jurídico norte-americano, entende-se as dificuldades que podem vir a surgir para a redação de uma lei autorizando a censura de determinados conteúdos disponibilizados online.

A fim de contornar esse obstáculo, preservando a liberdade de expressão e ao mesmo tempo garantindo a vítimas de pornografia de vingança uma forma de retirar da internet mídias que violem sua privacidade e intimidade, Burris (2014) aponta a decisão da Suprema Corte dos Estados Unidos no caso United States v. Stevens. A Corte destaca as áreas do discurso sobre as quais há permissão constitucional para que possam ser restringidas pela via legislativa. Alguns dos temas que podem ser restringidos são obscenidade, difamação, e discurso que incite iminente atividade ilegal. Segundo a Suprema Corte categorias de discurso não protegidas pela Primeira Emenda são aquelas consideradas "contendo um valor social tão insignificante na busca pela verdade que qualquer benefício que possa ser derivado delas é claramente superado pelo interesse social em ordem e moralidade $[\ldots]^{10}$. (BURRIS, 2014, p.2347)

A distribuição não consensual de mídias íntimas configura discurso obsceno, permitindo sua exclusão do âmbito de proteção garantido pela Primeira Emenda. Novamente, um precedente da Suprema Corte é utilizado para determinar se o material analisado é obsceno. Em Miller v. California (1973), a Corte formulou etapas para averiguar se o trabalho questionado caracterizaria ou não discurso obsceno. Embasada nos precedentes da Suprema Corte dos Estados Unidos mencionados, Burris (2014) propõe a criação de legislação federal criminalizando a prática de pornografia de vingança. A penalização, por meio de lei federal, da distribuição intencional de mídia íntima, sem o consentimento da pessoa retratada, reforçaria a proteção da privacidade dos indivíduos. Com a aprovação de uma lei de aplicação em todo o território norte-americano, as

\footnotetext{
9 "Amendment I - Congress shall make no law respecting an establishment of religion, or prohibiting the free exercise thereof; or abridging the freedom of speech, or of the press; or the right of the people peaceably to assemble, and to petition the Government for a redress of grievances."

10 " [...] of such slight social value as a step to truth that any benefit that may be derived from them is clearly outweighed by the social interest in order and morality" (Tradução nossa)
} 
vítimas de exposição involuntária em todos os Estados teriam as mesmas garantias legislativas para se defenderem em casos de pornografia de vingança.

Analisando os benefícios que poderiam decorrer de uma lei federal criminalizando a conduta, Bambauer (2014) distingue alguns pontos positivos e algumas falhas que dificultariam a implementação dos dispositivos legais pretendidos. Fatores que poderiam exprimir consequências benéficas da criminalização da pornografia de vingança são a estigmatização social, o aparato investigativo estatal e a exceção existente na Seção 230 do CDA para leis federais. Por um lado, o estigma associado à condenação penal poderia influenciar no modo como casos dessa natureza são percebidos socialmente. Indivíduos reconhecidos por promoverem a distribuição não consentida de fotos e/ou vídeos íntimos retratando outra pessoa, possivelmente, seriam associados ao estigma de criminosos, o que poderia representar perdas em suas relações sociais.

Por outro lado, Bambauer (2014) aponta obstáculos que poderiam, com alguma facilidade, tornar uma lei federal criminalizando a pornografia de vingança inócua. Entre eles estão a limitação de recursos estatais para investigação criminal, a baixa efetividade da legislação, e a dificuldade de responsabilizar provedores de aplicações. Uma primeira dificuldade estaria na alocação de recursos para investigações criminais, já que as pressões existentes para que promotores privilegiem a investigação de crimes que representem uma ameaça para a segurança nacional, ou que envolvam tráfico de drogas, crime organizado, entre outros temas de maior destaque social, importaria em baixa efetividade na apuração de casos de pornografia de vingança.

Mesmo que da criminalização da conduta decorresse a estigmatização social esperada, a legislação geraria poucos efeitos práticos, com baixos níveis de punição para aqueles que incorressem no comportamento criminoso. Este aspecto tornaria a lei incapaz de produzir resultados expressivos para as vítimas de pornografia de vingança. Considerando o grande dano causado às vítimas pela constante disponibilidade e reiterados compartilhamentos do material, a reparação advinda da responsabilização daquele que originalmente distribuiu a imagem e/ou vídeo de cunho íntimo demonstra-se insuficiente ante a extensão do prejuízo.

De modo diverso, Burris (2014) acredita que é possível assegurar maior proteção às vítimas criando uma exceção no Communications Decency Act para casos de pornografia de vingança. Baseada em precedentes da Suprema Corte, a autora caracteriza a distribuição de mídia íntima como discurso obsceno, visando garantir sua exclusão do escopo de proteção da Primeira Emenda para a liberdade de expressão. Em sua defesa pela promoção de alterações na Seção 230 do CDA, a fim de viabilizar a proteção de vítimas de pornografia de vingança, Burris (2014) afirma, ainda, que a 
lei deve ter como objetivo primordial apreender qual a expectativa razoável de privacidade ${ }^{11}$ que o indivíduo retratado na mídia íntima distribuída indevidamente tinha ao compartilhar o conteúdo.

Além dos conflitos apontados entre privacidade e liberdade de expressão, quando se discute formas de proteção de vítimas de pornografia de vingança. Outro ponto de tensão do debate está centrado no conflito entre privacidade, segurança e anonimato. A privacidade é um valor que pode ser entendido sob dois enfoques distintos. Tanto pode ser compreendido como um direito fundamental, com valor intrínseco, quanto pode ser avaliado como um valor instrumental. Segundo a corrente instrumentalista, a importância da privacidade decorre do fato de que ela propicia o exercício de outros valores fundamentais. Adotando-se essa perspectiva, “[...] a privacidade pode ser negociada ou limitada porque, ao fazê-lo, outros valores importantes serão promovidos ${ }^{12}$, (WALDO, 2007, p.66).

A proteção da privacidade e a garantia da segurança devem ser entendidos como valores complementares, que se limitam de modo a prevenir possíveis consequências negativas decorrentes do excesso de um ou outro. Por fim, cabe destacar que, entre as soluções aventadas na literatura para garantir a proteção de vítimas de pornografia de vingança, existem propostas sugerindo a implementação de um regime de notificação e retirada. Essa saída encontra inspiração no Digital Millenium Copyright Act (DMCA), que dispõe sobre a responsabilização de provedores em casos de violação de direitos autorias. Conforme previsto no DMCA, “[...] os provedores são considerados responsáveis pelos atos de seus usuários que infringirem direitos autorais se, uma vez notificados, não removerem o conteúdo questionado" (SOUZA, 2014, p.795).

Apesar de existirem muitas propostas buscando preservar a privacidade e reparar os danos causados a vítimas de pornografia de vingança, permanece difícil vislumbrar uma forma plenamente eficaz de abordar a questão. O regime de notificação e retirada do DMCA se aproxima da solução adotada pelo Marco Civil da Internet brasileiro, como veremos no próximo tópico, em que analisaremos os expedientes disponíveis no ordenamento jurídico brasileiro para o indivíduo que tem uma mídia íntima divulgada sem o seu consentimento.

\section{PROTEÇÃO DA PRIVACIDADE ONLINE NO BRASIL}

\footnotetext{
${ }^{11}$ Sobre a expectativa razoável de privacidade que um usuário da internet pode esperar, GAGNIER (2011) afirma que a jurisprudência versando sobre informações coletadas por provedores de acesso (ISPs - Internet Service Providers) e, em especial, o precedente United States v. Miller da Suprema Corte, consideram que não existe uma expectativa razoável de privacidade quanto a dados compartilhados com terceiros (provedores de acesso e/ou provedores de aplicações). Entretanto, as redes sociais tendem a criar espaços percebidos por seus usuários como privados, por meio de configurações de privacidade que permitem selecionar quem terá acesso a suas informações pessoais. A Autora reputa que a possibilidade de limitar o acesso do público em geral ao seu perfil em uma rede social cria uma razoável expectativa de privacidade ilusória.

12 " [...] privacy can be traded off or limited because doing so will promote other values that we hold dear". (Tradução nossa)
} 
Traçado o panorama norte-americano sobre "revenge porn", expõe-se o contexto brasileiro, apontando quais as possibilidades existentes na legislação pátria para a responsabilização daqueles que cometem pornografia de vingança e para a reparação dos danos causados às vítimas com o panorama legislativo brasileiro sobre os temas previamente discutidos. Apesar disso, o debate focado na distribuição não consensual de mídia íntima, no contexto brasileiro, ainda está limitado a iniciativas incipientes. Pode-se supor que a influência das normas culturais prejudica a percepção da relevância do tema, tendo em vista que a pornografia de vingança atinge majoritariamente mulheres, num país marcadamente machista.

A culpabilização das vítimas, atrelada à solução da abstinência, pode ser um fator que contribua para os esforços diminutos dedicados ao desenvolvimento de mecanismos eficientes para a proteção e a reparação dos danos causados a vítimas de pornografia de vingança. Por não guardar a mesma proeminência que detém no ordenamento jurídico dos Estados Unidos, a liberdade de expressão não representa, no sistema brasileiro, tão grande obstáculo na busca por soluções para a pornografia de vingança. Assim, a ponderação entre os referidos valores, para estabelecer qual deles deverá prevalecer no caso concreto, não tende de forma tão expressiva a privilegiar a liberdade de expressão.

A proteção da privacidade está assegurada no rol de direitos fundamentais elencados no art. $5^{\circ}$ da Constituição Federal de 1988. Seu inciso X prevê serem " [...] invioláveis a intimidade, a vida privada, a honra e a imagem das pessoas, assegurado o direito a indenização pelo dano material ou moral decorrente de sua violação". Essa proteção constitucional faz parte de um contexto maior, internacional diante da Convenção Americana sobre Direitos Humanos ${ }^{13}$ que garante, em seu artigo 11.2, a proteção da vida privada contra ingerências arbitrárias ou abusivas. O referido artigo ainda elenca os direitos de toda pessoa à honra e à dignidade.

Entre os direitos da personalidade, o Código Civil elenca em seu artigo $21^{14}$ a inviolabilidade da vida privada, reiterando a proteção concedida no ordenamento jurídico brasileiro ao direito à privacidade. $\mathrm{O}$ art. 12 do $\mathrm{CC} / 02$ dispõe que em caso de ameaça ou lesão a direito da personalidade o indivíduo poderá exigir a cessação do ilícito, bem como reclamar perdas e danos. Com fundamento nessa previsão, aquele que tiver direito da personalidade violado pode buscar pela via judicial a reparação pelo dano causado. Contudo, com base no artigo supramencionado, a vítima também poderá exigir a cessação do dano. Ou seja, poderá requerer que o indivíduo responsável pela distribuição do material íntimo seja compelido judicialmente a não repetir ou a não continuar

\footnotetext{
${ }^{13}$ Promulgada por meio do Decreto $n^{\circ} 678$, de 6 de Novembro de 1992.

14 Art. 21. "A vida privada da pessoa natural é inviolável, e o juiz, a requerimento do interessado, adotará as providências necessárias para impedir ou fazer cessar ato contrário a esta norma".
} 
a praticar o ilícito. Deste modo, o réu poderá ser instado a retirar a imagem e/ou vídeo que inseriu na rede, ou a não mais repetir o ato.

Apesar de representar um ganho para a vítima da distribuição de mídia íntima não consensual, a tutela inibitória não constitui reparação significativa para o indivíduo involuntariamente exposto. A natureza do ambiente virtual permite que os conteúdos disponibilizados online sejam replicados e compartilhados, em grande volume e rapidez. Isso significa que, mesmo que seja possível o responsável pela distribuição indevida retirar a mídia do site onde foi inicialmente inserida, permanecem as chances de que o material já terá se disseminado online, tornando sua exclusão total extremamente difícil. De forma mais específica sobre o uso da imagem, o art. 20 do CC/2002 garante que a exposição ou utilização poderá ser proibida a pedido do indivíduo retratado, se houver violação de sua honra, boa fama, respeitabilidade, ou se a imagem for empregada com fins comerciais. A disciplina civilista prevê que aquele que comete um ato ilícito, causando dano a outra pessoa, será responsável por reparar o dano causado, nos termos do caput do artigo 927 do Código Civil. Ainda, a indenização cabível deverá ser proporcional ao dano sofrido.

A regra geral para a imputação do dever de indenizar é a responsabilidade subjetiva. Isto é, aquele que cometer um ato ilícito, gerando dano a outrem, estabelecido por um nexo de causalidade, deverá reparar o indivíduo pelo dano suportado. Para tanto, há de se configurar o nexo de causalidade entre a conduta antijurídica e o dano apurado. Se o dano moral observado decorrer de um ato ilícito, evidenciado o dolo ou a culpa do agente, e caracterizado o nexo de causalidade entre os fatos, surge a obrigação de indenizar.

Entretanto, o parágrafo único do artigo 927 prevê uma exceção à regra. Nesta hipótese, a responsabilidade será objetiva, de forma que surge a obrigação de indenizar " [...] independentemente de culpa, nos casos especificados em lei, ou quando a atividade normalmente desenvolvida pelo autor do dano implicar, por sua natureza, risco para os direitos de outrem". Devido ao risco inerente à atividade, ou nos demais casos definidos em lei, a responsabilidade será objetiva. Isto significa que, para a responsabilização daquele que deu causa ao dano, não se exige a demonstração de culpa. Ocorrendo o dano, surgirá automaticamente a responsabilidade de indenizar para seu autor. A teoria da responsabilidade objetiva rege, especialmente, as relações de consumo. O Código Civil determina que a responsabilidade de empresas, por danos causados por produtos postos em circulação, independerá de culpa.

Também o Código de Defesa do Consumidor traz previsão semelhante, em seu artigo 14. O CDC prevê que não é necessário apurar a culpa do fornecedor de serviços para lhe imputar o dever de indenizar danos decorrentes do serviço. Assim, se o consumidor sofre um prejuízo em razão de defeito na prestação de serviço, o fornecedor será obrigado a reparar o dano, mesmo que não tenha 
concorrido culposamente para a ocorrência do dano. O provedor de aplicações pode ser enquadrado como fornecedor de serviço, nos termos do CDC, por manter uma relação de consumo com o usuário, mesmo que o serviço prestado seja gratuito. Porém, o entendimento adotado pelo Superior Tribunal de Justiça determina que a responsabilidade do provedor não é objetiva, em casos de informações inseridas na internet por terceiros.

Diante dessa posição jurisprudencial, a responsabilidade objetiva prevista no CDC não autoriza a responsabilização do provedor de aplicações, em casos de pornografia de vingança. A atividade do provedor de aplicações, para a prestação do serviço, não inclui a avaliação prévia do material distribuído na rede por cada usuário. Assim, a disponibilização online de imagens e/ou vídeos íntimos, sem o consentimento da pessoa retratada, não indica defeito no serviço prestado. $\mathrm{O}$ Marco Civil da Internet (Lei $\left.n^{\circ} 12.965 / 2014\right)$, por sua vez, aprovado em 2014, figura nesse contexto como uma lei inovadora, reconhecida internacionalmente por sua posição de vanguarda. Trazemos uma análise quanto ao modelo previsto na lei para a responsabilização por conteúdos danosos inseridos na internet. Seu processo de elaboração contou com consultas públicas, por meio das quais a população pode dar sugestões, opinar, participando da construção do texto da lei por meio de uma plataforma online.

Segundo o art. 18 não cabe a responsabilização civil do provedor de acesso por danos causados pelo conteúdo disponibilizado online por terceiros. Já o provedor de aplicações somente poderá ser responsabilizado nessas circunstâncias, caso, após receber ordem judicial específica, não retire o conteúdo violador da internet. Ao provedor de aplicações será determinado um prazo para a retirada do material apontado como infringente, bem como serão respeitados os limites técnicos do serviço para o cumprimento da ordem judicial. Não obstante o texto do art. 19 do MCI defina tais garantias ao provedor de aplicações, para viabilizar o atendimento ao comando judicial, na prática a compreensão das limitações técnicas do serviço pode representar um ponto desafiador para a concessão de um efetivo provimento jurisdicional.

De qualquer modo, a Lei ainda assegura ao provedor de aplicações que a ordem judicial deverá indicar clara e especificamente o material a ser eliminado, possibilitando sua localização de forma inequívoca. Resta assegurada a liberdade de expressão online, vedada a censura pelos provedores de aplicações. Os usuários que desejarem ver um conteúdo retirado da internet, por entenderem que viola seus direitos, devem buscar pela via judicial tal decisão. Não é possível exigir diretamente dos provedores de aplicações a retirada arbitrária de determinado material, produzido por terceiros, disponibilizado em suas plataformas. Tampouco pode o provedor de aplicações ser responsabilizado pelo conteúdo a ser eliminado, desde que cumpra devidamente com a ordem judicial de remoção. 
Contudo, ante a natureza das relações que se desdobram no ambiente virtual, o MCI trouxe uma exceção para a impossibilidade de responsabilização do provedor de aplicações por conteúdo de terceiros. Em casos em que haja violação da intimidade, se o provedor de aplicações não tornar indisponível o conteúdo violador, depois de notificado pela pessoa retratada na mídia para tanto, será responsabilizado subsidiariamente pelo dano causado. Nos termos do artigo 21 do MCI, o indivíduo que tiver sua intimidade violada, com a divulgação de imagens, vídeos, ou quaisquer materiais contendo nudez ou de cunho sexual, não precisará recorrer ao Poder Judiciário para que o conteúdo seja retirado da internet. Bastará notificar o provedor de aplicações, que fica então obrigado a remover o material indicado. Essa ressalva prevista na lei assegura que, em casos de pornografia de vingança, o procedimento para a retirada da mídia íntima da rede seja mais célere, prescindindo de pronunciamento judicial para que o conteúdo seja removido. O artigo exige somente que a cena retratada na mídia seja de caráter privado, e que a divulgação tenha ocorrido sem autorização de pessoa que tome parte nos atos revelados.

Assim como para os casos em que a responsabilidade civil do provedor de aplicações somente decorre de descumprimento de ordem judicial, também o artigo 21 elenca como requisitos para instruir a notificação, sob pena de nulidade, que a pessoa forneça elementos para viabilizar a identificação do material a ser eliminado, além de demonstrar sua legitimidade para a apresentação do pedido. Mesmo dispensando decisão prévia do Poder Judiciário determinando a remoção do conteúdo questionado do ambiente virtual, persiste, igualmente, a reserva de que deverão ser observados os limites técnicos do serviço do provedor de aplicações para a indisponibilização do material violador. O procedimento para retirada de mídias íntimas distribuídas online, sem o consentimento da pessoa retratada, previsto no MCI, objetiva minorar os danos causados ao indivíduo exposto. Caso o provedor de aplicações não cumpra com a notificação apresentada pela vítima, será responsabilizado subsidiariamente pelo prejuízo, artifício que visa compelir os provedores a agirem de forma diligente na retirada do material da rede.

Apesar dos méritos do mecanismo colocado em vigor pela lei, permanece a dificuldade em limitar a extensão dos danos causados às vítimas de pornografia de vingança. A natureza da internet permite que o conteúdo, indevidamente disponibilizado online, seja reproduzido e compartilhado inúmeras vezes, instantaneamente. Isto também torna mais complexa a atuação dos provedores de aplicações, ao intentarem indisponibilizar a mídia íntima, após notificados. Para que o sistema funcione com maior efetividade, um aspecto fundamental é impedir que um conteúdo anteriormente removido volte a ser disponibilizado online. É necessário, então, que os próprios provedores de aplicações desenvolvam formas de vedar a reinserção, em suas plataformas, de mídias íntimas já identificadas como materiais violadores da intimidade de determinado indivíduo. 
Por fim, cabe apontar que não existe no ordenamento jurídico brasileiro um tipo penal específico para quem pratica pornografia de vingança. Aqueles que desejarem buscar reparação, por meio da persecução penal, podem alegar serem vítimas de crime contra a honra, conforme os artigos 138 a 145 do Código Penal. Abaixo, realiza-se uma análise comparativa dos principais pontos na regulação da matéria, apresentados no tópico 4 e 5 deste artigo, tanto sobre âmbito do ordenamento jurídico brasileiro, quanto na legislação norte-americana.

Tabela 1. Comparação Ordenamento Jurídico Brasil x EUA

\begin{tabular}{|c|c|c|}
\hline & BRASIL & EUA \\
\hline $\begin{array}{c}\text { Responsabilidade civil de } \\
\text { provedores }\end{array}$ & $\begin{array}{l}\text { Provedor de acesso não é } \\
\text { responsável por conteúdo de } \\
\text { terceiros (artigo } 18 \text { do Marco } \\
\text { Civil da Internet). }\end{array}$ & $\begin{array}{l}\text { Não são responsáveis por } \\
\text { informação disponibilizada } \\
\text { por terceiros (seção } 230 \text { do } \\
\text { CDA). }\end{array}$ \\
\hline $\begin{array}{l}\text { Hipótese excepcional de } \\
\text { responsabilização }\end{array}$ & $\begin{array}{l}\text { Provedor de aplicações é } \\
\text { responsável, se não atender } \\
\text { notificação judicial para } \\
\text { retirar o conteúdo (artigo } 19 \\
\text { do Marco Civil). }\end{array}$ & $\begin{array}{l}\text { Em caso de violação de direito } \\
\text { autoral, o provedor é } \\
\text { responsável se não retirar o } \\
\text { conteúdo após notificação } \\
\text { judicial (seção } 202 \text { do } \\
\text { DMCA). }\end{array}$ \\
\hline $\begin{array}{l}\text { Responsabilidade em caso } \\
\text { de pornografia de vingança }\end{array}$ & $\begin{array}{l}\text { O provedor de aplicações é } \\
\text { responsável, se não retirar o } \\
\text { conteúdo após ser notificado } \\
\text { pela pessoa exposta ou seu } \\
\text { representante legal (artigo } 21 \\
\text { do Marco Civil). }\end{array}$ & $\begin{array}{l}\text { Não existe } \\
\text { específica. }\end{array}$ \\
\hline
\end{tabular}




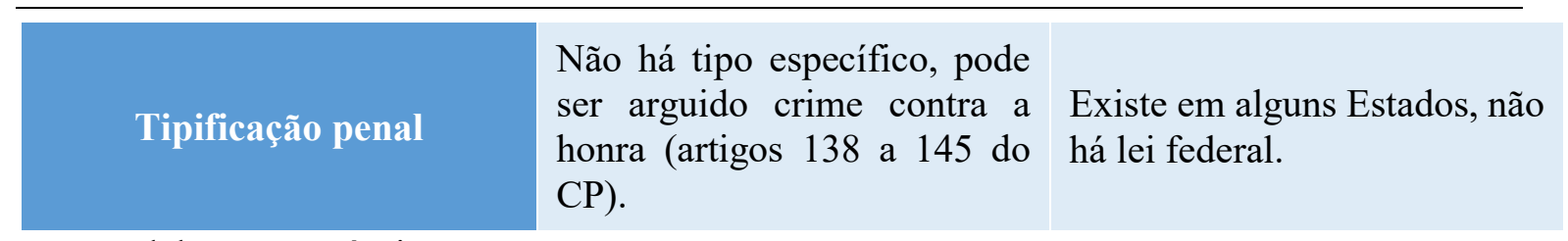

Fonte: elaboração própria

Considerando o quadro retratado acima, podemos concluir que as leis brasileiras garantem maior proteção às vítimas de pornografia de vingança, do que o ordenamento jurídico norteamericano. De qualquer forma, ainda existem muitos desafios a serem enfrentados pela legislação pátria. Apesar do Marco Civil da Internet assegurar um procedimento mais célere para a remoção de mídias íntimas, indevidamente distribuídas online, a responsabilização do provedor de aplicações só ocorrerá se não atender à notificação da vítima. Contudo, a retirada, da rede, do material violador está sujeita às limitações técnicas do serviço. Caso o provedor comprove ter agido de forma diligente, no âmbito de suas capacidades técnicas, para remover o conteúdo, não poderá ser responsabilizado.

\section{CONSIDERAÇÕES FINAIS}

O debate sobre a pornografia de vingança é essencial para se buscar soluções alternativas para coibir a prática e enfrentar a questão. As dificuldades apresentadas por essa tarefa são extensas, abrangendo desde peculiaridades técnicas quanto ao funcionamento da internet e a disseminação de conteúdos em meio digital, até a técnica legislativa, ante a complexidade de se inserir no ordenamento jurídico atual mecanismos capazes de desestimular e punir tais condutas com eficácia, mas preservando a liberdade de expressão e demais garantias fundamentais dos usuários na rede. $\mathrm{O}$ direito à privacidade tem contornos difíceis de serem delineados, variando conforme normas sociais, bem como de acordo com o local em que ocorre a situação em análise. Dessa forma, para a apuração da existência de violação da privacidade de um indivíduo será essencial uma análise conjunta do contexto fático e das normas sociais vigentes, que demonstrarão a expectativa de privacidade que razoavelmente se poderia esperar.

A tarefa de distinguir entre público e privado torna-se ainda mais árdua com a consolidação da internet, enquanto meio de comunicação livre e acessível a grande parte da população global. No meio virtual há pouca clareza acerca da privacidade das relações empreendidas, em especial pela falsa sensação de que as informações são trocadas unicamente com o destinatário, ficando oculto o provedor de aplicações, intermediário que viabiliza a interação entre os usuários. Essa aparente sensação de privacidade pode tornar os usuários mais displicentes quanto à proteção de sua privacidade online, e modifica a expectativa razoável de privacidade que se pode esperar na 
rede. Nesse ponto surgem novos desafios, entre eles: comprovar que o material questionado, de fato, violou a privacidade da pessoa exposta, análise casuística, que deverá considerar onde a mídia íntima foi produzida, por quem, e como veio a ser distribuída na internet; identificar o indivíduo que disponibilizou o conteúdo violador online; e remover totalmente o material, que se dissemina rapidamente na rede, tudo isso sem criar empecilhos que inviabilizem a atividade comercial do provedor de aplicações.

Diferentemente do que ocorre nos Estados Unidos, onde a legislação traz previsão expressa, há vários anos, quanto à ausência de responsabilidade dos provedores de aplicações por danos causados por terceiros, no Brasil regra similar só surgiu com o Marco Civil da Internet, em 2014. A regra geral estabelecida pela lei, segundo a qual o provedor de aplicações só poderá ser responsabilizado caso não cumpra com decisão judicial determinando que indisponibilize o conteúdo infringente, encontra somente uma exceção. A ressalva prevista no art. 21 do MCI visa, justamente, limitar os danos suportados por vítimas de pornografia de vingança, prevendo procedimento mais célere para a retirada de mídias íntimas da internet.

Por mais que a solução penal possa trazer resultados, devido ao estigma relacionado à condenação penal, não aparenta ser a mais efetiva para a resolução do problema. A criação de um novo tipo penal pode não produzir os efeitos pretendidos, diante do assoberbamento do Poder Judiciário, atrelado às condições precárias do sistema penitenciário nacional. Não existe resposta simples ou rápida para evitar que mais mulheres tenham mídias íntimas divulgadas online, com o fim de relacionamentos. O MCI busca de forma louvável proteger as vítimas de pornografia de vingança, e é importante que suas previsões sejam observadas e atendidas, por provedores de aplicações, vítimas e pelo Poder Judiciário. As indenizações pelos danos morais sofridos, quando imputadas aos provedores de aplicações, devem ser de valores compatíveis com o poderio econômico do provedor. Somente assim pode-se influenciar o comportamento dos provedores, para que atuem conforme à lei, protegendo as vítimas.

A solução mais eficaz para o problema da pornografia de vingança, com a transformação das normas sociais vigentes, acontece por alterações ao longo do tempo nos preceitos aceitos culturalmente. Em especial, é preciso que a sexualidade feminina não seja vista de forma depreciativa, o que influi na extensa maioria dos casos de exposição involuntária online terem como vítimas mulheres. Enquanto aspectos culturais não permitirem que homens e mulheres expressem suas sexualidades sem que as consequências, principalmente para as mulheres, ameacem sua privacidade, e a harmonia de seus convívios social e profissional, caberá à legislação promover avanços na proteção das vítimas de pornografia de vingança, assegurados por meio do judiciário, quando assim se fizer necessário. O trabalho não esgota o tema que deve ser mais explorado, para 
se trazer novas alternativas para a uma efetiva proteção dos usuários face a pornográfica de vingança, apresenta-se, portanto, iniciais apontamentos para a continuidade da pesquisa.

\title{
ONLINE PRIVACY PROTECTION IN REVENGE PORN
}

\begin{abstract}
This paper presents a comparative study of revenge pornography between Brazil and the United States, evaluating the effectiveness of existing instruments for victims' protection and compensation of damages, from qualitative analyses. The following research questions are: How does the concept of privacy apply to the virtual environment? How did technologies enable the development of new forms of intimacy, as well as practices such as revenge porn? Analyze the right to privacy within the conception of public and private sphere in the virtual environment and as new forms of intimacy in the context, pointing possible ways for improvements in the current legislation on the subject.
\end{abstract}

Keywords: revenge porn; right to privacy; Civil Rights Framework for the Internet; Brazil; USA.

\section{REFERÊNCIAS BIBLIOGRÁFICAS}

ASSEMBLEIA GERAL DAS NAÇÕES UNIDAS. Resolução 217 A (III), 10 de dezembro de 1948. Declaração Universal dos Direitos Humanos. Paris, 1948. Disponível em:

http://unesdoc.unesco.org/images/0013/001394/139423por.pdf. Acesso em: 25 jan. 2018.

BAMBAUER, Derek E. Exposed. Minnesota Law Review, v. 98, n. 6, jun. 2013/2014, p. $2025-$ 2102.

BURRIS, Aubrey. Hell Hath no Fury like a Woman Porned: Revenge Porn and the Need for a Federal Nonconsensual Pornography Statute. Florida Law Review, v. 66, n. 6, 2014, p. 2325-xiv.

CHOI, Bryan H. The Anonymous Internet. Maryland Law Review, v. 72, n. 2, 2012/2013, p. 501570. Disponível em: http://goo.gl/tqljIq. Acesso em: 21 ago. 2018.

CODING RIGHTS. Safer nudes: A Sexy Guide to Digital Security. Disponível em: http://www.codingrights.org/pt/manda-nudes/. Acesso em: 31 mai. 2018.

CRESPO, Marcelo Guardia. No te Metas en mi Vida, Privacidad e Intimidad em los Medios. Punto Cero, v. 19, n. 28, 2014, p. 33-44.

DONEDA, D. Da privacidade à proteção dos dados pessoais. Rio de Janeiro: Renovar, 2006.

ESTADOS UNIDOS DA AMÉRICA. Bill of Rights, 04 de março de 1789. Nova Iorque, 1791. Disponível em: http://goo.gl/JQ1Z. Acesso em: 29 abr. 2018. 
. Public Law $n^{\circ}$ 104-104, 08 de fevereiro de 1996. Telecommunications Act of 1996. Washington, D.C., 1996. Disponível em: https://goo.gl/8bqNgG. Acesso em: 29 abr. 2018.

. Public Law $n^{\circ}$ 105-304, 28 de outubro de 1998. Digital Millennium Copyright Act. Washington, D.C., 1998. Disponível em: https://goo.gl/z1yh0u. Acesso em: 29 abr. 2018.

. Supreme Court. 559. United States v. Stevens. Chief Justice Roberts. 2010. Disponível em: http://www.supremecourt.gov/opinions/09pdf/08-769.pdf. Acesso em: 08 abr. 2018.

GAGNIER, Christina M. On Privacy: Liberty in the Digital Revolution. Journal of High Techonology Law, v. 11, n. 2, 2011, p. 229-279.

HOLLAND, H. Brian. Privacy Paradox 2.0. Widener Law Journal, v. 19, n. 3, 2009-2010, p. 893932. Disponível em:

http://heinonline.org/HOL/Page?handle=hein.journals/wjpl19\&div=\&collection=\&collection=jou rnals\#\&id=901. Acesso em: 01 set. 2018.

NISSENBAUM, Helen. Privacy as Contextual Integrity. Washington Law Review, v. 79, 2004, p. 101-139.

NUSSBAUM, Martha Craven. The Offensive Internet: Speech, Privacy and Reputation.

Cambridge: Harvard University Press, 2012. 308 p. ProQuest ebrary. Acesso em: 25 mar. 2016.

SOLOVE, Daniel J. Future of Reputation: Gossip, Rumor and Privacy on the Internet. New Haven: Yale University Press, 2007. 257 p. ProQuest ebrary. Acesso em: 23 mar. 2018.

SOUZA, Carlos Affonso Pereira de. Responsabilidade Civil dos Provedores de Acesso e de Aplicações de Internet: Evolução Jurisprudencial e os Impactos da Lei no 12.965/2014 (Marco Civil da Internet). In: LEITE, George Salomão; LEMOS, Ronaldo (Org.). Marco Civil da Internet. 1 ed. v. 1. São Paulo: Atlas, 2014. p. 791-816.

STEPANOVIC, Ivana. Modern Technology and Challenges to Protection of the Right to Privacy. Annals of the Faculty of Law in Belgrade - International Edition, v. LXII, n. 3, 2014, p. 167-178.

WALDO, James; LIN, Herbert; MILLETT, Lynette I. Engaging Privacy and Information Technology in a Digital Age. Washington: National Academies Press, 2007. 450 p. ProQuest ebrary. Acesso em: 23 mar. 2018.

Trabalho enviado em 24 de janeiro de 2019 Aceito em 06 de fevereiro de 2020 